\title{
Oedipus to Jack the Ripper
}

\author{
The Alternative Journal Club
}

\author{
Gillian Combe, Sara Cunningham and Anne Read
}

Since the first journal clubs were started this educational tool has been used by the medical profession with varying degrees of success (Linzer, 1987). Journal clubs allow trainees to review a piece of published research and discuss it with senior colleagues. They are frequently plagued by poor attendance and perceived as less than exciting, and at worst frankly boring. The enormous choice of journals compared with 100 years ago and the diversity of the media available mean that journal clubs should look towards developing in their format. Various methods have been tried to improve attendance, percetved relevance and enjoyment, such as evidence-based medicine reviews (Gilbody, 1996), teaching critical appraisal skdlls, and using structured review methods (Burstein et al, 1996). Sidorov (1995) surveyed 131 postgraduate programmes in the eastern USA and found the following features were associated with high attendance and continuous existence of journal clubs: smaller residency programmes, making attendance mandatory, providing food and promoting original research articles.

For some time, the Department of Psychiatry's journal club in Plymouth had experienced attendance problems. The traditional format was followed of a recent journal article being presented and then discussed - or not, as the lack of motivation had spread even to those who were due to present the articles. This led to cancellations at short notice, lateness of arrival and poorly prepared presentations. Senior trainees identified a need to regenerate enthusiasm. This had to be achieved while adhering to the Royal College of Psychiatrists' guidelines of not less than 20 'conventional' journal clubs per year (Royal College of Psychiatrists, 1996). The clinical tutor decided to update the journal club and offer an opportunity to use imagination and creativity, as well as developing the skill of critical evaluation.

\section{Method}

The conventional journal club format was followed for half the sessions, with the option of making an alternative presentation fortnightly, allowing an innovative and personal choice of material. The subject of the alternative presentations had to be relevant to psychiatry but no other restrictions were laid down.

With the clinical tutor's agreement, a trial of this method was performed for six months. The medium used, presentation style, source of information and context of each presentation were recorded. At the end of the hour, the group had a discussion and rated the material using a Likert scale ( $1=$ no interest/relevance, $5=$ very interesting/relevant) in terms of:

(a) Relevance to psychiatry.

(b) Relevance to general practice (included as some of our trainees are future general practitioners).

(c) Clinical interest.

(d) Academic interest.

(e) General interest.

After six months, each participant was asked how many conventional and/or alternative presentations they could remember and the impact they felt each presentation had on them. Mean scores for each type of presentation were analysed using the Student's $t$-test $(P<0.05$ was considered significant).

\section{Results}

The journal club involved between one and three consultants, two senior registrars and eight senior house officers (with psychiatry training ranging from 6-18 months). All trainees had the opportunity to present one conventional and one alternative journal club and the changed format meant that, unusually, senior registrars and consultants also gave presentations. There was no difference in attendance between the two types of journal club. Table 1 shows the types of presentations and ratings, with brief descriptions of the more unusual ones. Alternative journal clubs were significantly different from their conventional counterparts for relevance to psychiatry and general interest, but there were no differences in the categorles of relevance to general practice, clinical or academic interest. 


\begin{tabular}{|c|c|c|c|c|c|c|}
\hline \multirow[b]{2}{*}{ This } & \multirow[b]{2}{*}{ Medium } & \multicolumn{5}{|c|}{ Ratings } \\
\hline & & Poy & GP & Clin & Acad & Gon \\
\hline \multicolumn{7}{|l|}{ Conventional } \\
\hline St John's wort for depression & Journal & 4 & 3 & 3 & 4 & 4 \\
\hline Long-term outcome of neurotic illness in general practice & Journal & 4 & 5 & 4 & 4 & 4 \\
\hline Self-damaging and addictive behaviour in bulimia nervosa & Journal & 5 & 4 & 4 & 3 & 3 \\
\hline $\begin{array}{l}\text { Implications of the World Health Organization's study of mental illness } \\
\text { in general health care for training primary care staff }\end{array}$ & Journal & 3 & 4 & 3 & 3 & 4 \\
\hline $\begin{array}{l}\text { Paroxetine versus clomipramine in the treatment of obsessive- } \\
\text { compulsive disorder }\end{array}$ & Journal & 4 & 3 & 4 & 4 & 3 \\
\hline Rehabilitation for patients suffering from depression & Journal & 3 & 3 & 5 & 2 & 5 \\
\hline Monitoring psychosis in general practice: a controlled trial & Journal & 4 & 5 & 3 & 4 & 3 \\
\hline Use of high dose antipsychotic medication & Journal & 5 & 4 & 5 & 5 & 5 \\
\hline Cognitive processing of adverse experience & Journal & 3 & 2 & 2 & 2 & 2 \\
\hline \multicolumn{7}{|l|}{ Alternative } \\
\hline $\begin{array}{l}\text { 'Anybody out there' (presenting senior house officer speaking about } \\
\text { eating disorders on youth programme) }\end{array}$ & Video & 5 & 5 & 4 & 3 & 5 \\
\hline Jack the Ripper and Dracula (discussion of psychiatric diagnosis) & Book & 4 & 3 & 4 & 3 & 5 \\
\hline $\begin{array}{l}\text { 'Goldilocks and the three bears' (psychodynamic interpretations } \\
\text { of traditional fairy story) }\end{array}$ & Book & 5 & 5 & 4 & 4 & 5 \\
\hline Body language (recognising and interpreting) & Video & 5 & 5 & 5 & 2 & 5 \\
\hline $\begin{array}{l}\text { Oedipus and Electra (the original Greek myths and explanation of } \\
\text { historical and sociological context) }\end{array}$ & Story & 5 & 2 & 4 & 5 & 5 \\
\hline Animal virus found in depressed people (article from Nature) & Journal & 4 & 2 & 4 & 4 & 5 \\
\hline \multicolumn{7}{|l|}{ Mean scores } \\
\hline Conventional & & $3.9^{*}$ & 3.7 & $3.7^{8}$ & $3.4^{5}$ & $3.7^{*}$ \\
\hline Alternative & & 4.7 & 3.7 & 4.2 & 3.5 & 5 \\
\hline
\end{tabular}

" $P<0.05$. "not significant $P>0.05$. Psy, relevance to psychiatry; GP, relevance to general practice; Clin, clinical interest; Acad, academic interest; Gen, general interest.

After six months, trainees remembered $25 \%$ $(2.5 / 10)$ of conventional presentations compared with $64.5 \%(3.87 / 6)$ of the alternative presentations, which also had greater impact on trainees. The most obvious but least measurable outcome was the change in people's attitude to the journal club. It has become a pleasant event and is no longer a chore for the presenter. Attendance rates among junior staff were greatly improved in comparison with the previous six months. The results were presented in the medical audit meeting to encourage greater attendance from senior medical staff.

\section{Discussion}

It is uncommon for doctors to be allowed to use their creativity at work, and presenters seized the opportunity with enthusiasm. This allowed journal club to become more friendly and supportive as well as fulfilling a training requirement. There was a tremendous sense of ownership of each presentation, each person taking great pride in their achievement, with improvement in quality spreading to the conventional presentations. It was fascinating, as time went on, to discover the material which colleagues brought to the group.
Members of the group explored different media, including the return of storytelling as an educational tool. This is just as valuable a means of communication now as when the story of Oedipus was recounted centuries ago. There was also a personal element in the choice of material, not least in one person's showing of a video on eating disorders, in which she had taken part some years previously.

After each presentation, 20 minutes were allocated for discussion: the amount and quality of discussion improved, with both types of presentation, and the nature of the discussion altered. Previously it had concentrated on study design, statistical analysis and scientific materi$\mathrm{al}$, now sociological and psychodynamic issues were frequently also debated and evaluated. It was particularly interesting that conventional papers led to more creative discussions than before. The alternative journal clubs were thought to be more relevant to psychiatry and we wonder why this should be so. It may be that the information was presented in a more accessible way that related to people's experiences or that the issues were more relevant to psychiatric practice on a day to day basis, leading one to suggest that the current focus on journals is too restrictive. It is impossible to 
answer these questions but they should provoke debate about change.

Comments such as 'room for improvement', during a feedback session from previous trainees, had been an incentive for change and six months later the reward was that the "journa club very much enjoyed". Trainees noted that although the alternative presentations were more enjoyable to make, they were not seen as an easy option because presentation of a conventional article tends to follow an identifiable format, whereas the alternative may not.

It is unfortunate that the purely conventional approach used in the previous six months had not been audited in order to make comparison. However, the objective was not a scientific study but a trial of an alternative teaching method. One potential bias is the influence of consultants over the trainees when discussing ratings of interest and relevance but since the clinical tutor's presentation's relevance to general practice was only given $2 / 5$, we were perhaps not overly inhibited!

\section{Conclusion}

Senior trainees recognised that the attendance at journal club was poor and that the classical format did nothing to improve this. The approach described tried to remedy this situation. General practice and psychiatric trainees responded with equal enthusiasm, which implies this is a valuable form of professional training for all working in psychiatry. We are in no doubt that it has transformed our journal club into an enjoyable event and we shall continue to use this format. We hope that it will complement other current innovations, for example, evidence-based journal clubs. In the future perhaps journal clubs will become forums for exchange of information and not just passive learning events.

\section{References}

BURSTEIN, J. L., HOLlander, J. E. \& BARLAS, D. (1996) Enhancing the value of journal club: use of a structured review instrument. American Joumal of Emergency Medicine, 14, 561-563.

GILBODY, S. (1996) Evidence-based medicine. An improved format for journal clubs. Psychiatric Bulletin, 20. 673-675.

LINZER, M. (1987) The journal club and medical education: Over one hundred years of unrecorded history. Postgraduate Medical Journal, 63, 475-478.

ROYAL COLLEGE OF PSYChIATRISTS (1996) Statement on Approval of Training Schemes for General Professional Training for the MRCPsych (Court of Electors/General Professional Training Committee). London: Royal College of Psychiatrists.

SiDOROV, J. (1995) How are internal medicine residency journal clubs organised, and what makes them successful? Archives of Internal Medicine, 165. 1193-1197.

Gillian Combe, Senior House Officer in Psychiatry, Barrow Hospital, Barrow Gurney, Bristol BS48 3SG; *Sara Cunningham, Senior Registrar in Psychiatry, Glenbourne Unit, Morlaix Drive, Derriford, Plymouth PL6 5AF; and Anne Read, College Tutor and Consultant Psychiatrist in Substance Misuse, Damerel House, Damerel Close, Maddon Road, Devonport PL1 4JZ 